\title{
Workshop Ethics and Morality in Business Informatics (Workshop Ethik und Moral in der Wirtschaftsinformatik - EMoWI'19)
}

\author{
Jens Gulden ${ }^{1}$, Alexander Bock ${ }^{1}$, Sergio España ${ }^{2}$ \\ ${ }^{1}$ University of Duisburg-Essen, Research Group Enterprise Modeling and Information \\ Systems, Essen, Germany \\ \{jens.gulden, alexander.bock\} @uni-due.de \\ ${ }^{2}$ Utrecht University, Department of Information and Computing Sciences, Utrecht, \\ The Netherlands \\ s.espana@uu.nl
}

\begin{abstract}
The aim of the first edition of the EMoWI workshop was to establish a new forum for Business Informatics researchers and practitioners to reflect on the various ways in which the concern with business information systems and digital technologies gives rise to questions and issues with an ethical dimension. The several contributions of the workshop have made it plain that ethical questions indeed crop up in many fields of Business Informatics, ranging from specific research objects such as digital platforms to methodological presuppositions of the discipline at large. This chapter provides an overview of the background and the contributions of the EMoWI workshop 2019.
\end{abstract}

Keywords: Ethics, Values, Morals, Moral Philosophy, Business Informatics, Information Systems.

\section{Introduction}

According to Immanuel Kant, ethics is concerned with the question, "What ought I to do?", as opposed to the other two basic questions "What can I know?" and "What may I hope?" [1, p. 635, AK 833]. "What ought I to do as a Business Informatics researcher?" was therefore the leading question of the workshop Ethics and Morality in Business Informatics (EMoWI'19), held in its first edition at the $14^{\text {th }}$ International Conference on Wirtschaftsinformatik (WI 2019), in Siegen.

The idea for the workshop emerged from the recognition that while the examination of ethical questions has received a fair amount of attention in specific branches of information systems research, computer science, and the engineering sciences (see, e.g., [2, Part V] [3]), these examinations have tended to be underrepresented in major Business Informatics conferences in recent years. Yet the need for ethical reflections is more pressing than ever, given that information systems and digital technologies pervade both private and professional life to an unprecedented degree. The many developments in digital technologies bring forward classical problems of moral

$14^{\text {th }}$ International Conference on Wirtschaftsinformatik,

February 24-27, 2019, Siegen, Germany 
philosophy in new guises, as well as genuinely new species of situations in which good and bad, right and wrong conduct needs to be distinguished.

These developments pose significant challenges for the discipline of Business Informatics. Given that Business Informatics is conventionally expected to develop new ways of dealing with the emergent opportunities and challenges in a socially and technologically evolving society, the discipline cannot focus on the design of sociotechnical information systems in an instrumental sense alone. Instead, Business Informatics also has the responsibility to develop new ways of meeting the diverse and complex ethical ramifications of the use and design of information systems in society with prudence and responsibility. Our motivation in organizing this workshop was to advance the study of such moral responses to a rapidly changing world, and to promote reflections on the consequences for Business Informatics in research, teaching, and the public sphere.

\section{Central Themes and Challenges of Ethics in Business Informatics}

The discipline of Business Informatics is rife with ethical questions and issues. In common with its principal subject - the understanding and development of sociotechnical information systems - ethics and morality in Business Informatics can be studied from a variety of perspectives. These perspectives may concern the actual research objects of the discipline, or they may concern meta-scientific, methodological issues. On the level of concrete research objects, many areas of Business Informatics are bound up with ethical issues. For example, the design of artifacts and methods of Business Informatics has an ethical dimension, as the developed artifacts will typically have normative consequences for the behavior of people developing and operating business information systems. Likewise, the study of observable behavior between humans and software systems can investigate a diverse range of moral aspects, as information systems in many ways affect the actions, perceptions, and language of people involved with them. It is also worthy of examination whether conventional selfconceptions of professionals in Business Informatics embody moral, or perhaps morally problematic, premises. On a methodological level, in turn, ethical questions can concern basic assumptions and paradigms inherent in the research methods of Business Informatics.

It would be hopeless to attempt to provide a more exhaustive review of ethical questions in Business Informatics here. To make our case more tangible, we instead wish to highlight two general areas in which both classical and novel ethical questions arise in particular.

Decision Support in Information Systems. It is conventionally assumed that decision support is one of the basic tasks of computerized information systems. The history of Business Informatics is inextricably entrenched with Management Studies and Economics, where the leading conception of rational decision making has long been the expected utility model in different variants [4]. When applied to decision problems with an ethical dimension, this model naturally lends itself to a consequentialist 
conception of moral philosophy, famously advanced, for example, by Bentham [5] where alternatives are evaluated by the aggregated amount of pleasure or happiness obtained. However, such moral philosophies tend to neglect absolute rights and wrongs, such as the unalterable obligation not to kill. Such absolute principles are emphasized by deontologist moral theories, such as Kant's moral philosophy [6]. It is a question worth considering whether ordinary forms of decision support implemented in contemporary information systems implicitly adopt specific species of moral philosophies - and whether this has an effect on the moral evaluation of the courses of action recommended by these systems.

The Ethics of Developing and Using Business Informatics Artefacts. Humans and organizations shape the technology they design and implement, infusing their values into the resulting artefacts. In turn, those technological artefacts shape human experience and society. Value sensitive design is a theoretically grounded approach to the design of technology that systematically accounts for human values throughout the design process [7]. Neglecting the role of ethical and human values in business informatics product developments does not make those projects and products valuefree. Moreover, we are witnessing a recent increase of interest in researching the role and effects of ethics and values in software engineering [8] [9]. Researchers formulate questions related to the prominent values of software engineers themselves [10], the ethical concerns of software development organizations (e.g. diversity, workplace quality), and how software development processes should account for ethical values. Business Informatics, with its focus on supporting business management and operations, offers additional research questions, such as how software can contribute to increasing enterprise responsibility [11].

Overall, it is evident that ethical questions are deeply rooted in basic presuppositions and research objects of the field of Business Informatics.

\section{Contributions of the Workshop}

The contributions to this workshop address a rich spectrum of the ethical and valuerelated problem areas in Business Informatics outlined above. Out of seven submissions, after careful review by our program committee members, we have selected five papers for presentation at the workshop and publication in the workshop proceedings.

Paper 1. In studying how information systems can be used to improve human welfare, it is instructive to consider how classical and contemporary philosophical traditions have answered related questions. The paper "Doing Good Better: What We Can Learn from Effective Altruism" by Alexander Herwix demonstrates how the core ideas of a recent movement with philosophical and anthropological roots, effective altruism, can be applied in the field of Business Informatics. Effective altruism, making the case for a deliberate and measured use of resources so as to generate the greatest human benefits possible, provides a number of practices and principles to help promoting good in different areas. Applying two core ideas from effective altruism, 
'Shared Goals, Principles and Measures' and 'Cause Neutrality and Focus Area Selection', to the field of Business Informatics, the paper by Alexander Herwix proposes a number of reorientations for the discipline so that it may achieve more altruistic impact than it has had to date.

Paper 2. A central aim of Business Informatics is the design of new artifacts to support the development and use of information systems, commonly referred to as Design Science Research (DSR). Whether recognized or not, the design of artifacts is necessarily laden with ethical decisions. To promote awareness and evaluation of valuerelated design decisions in DSR projects the approach Value Sensitive Design (VSD) has been advanced in the literature. The paper "Value Sensitive Design in Design Science Research Projects: The Cases of Affective Technology and Healthcare Technology" by Oliver Heger reports on how VSD has been applied in two recent DSR projects and reflects on the lessons learned. The paper finds that VSD can indeed help identify, systematize, and assess value-laden design decisions and related conflicts in DSR projects. At the same time, the author stresses that more work is needed to obtain a better understanding of how approaches like VSD can raise Business Informatics researchers' awareness of ethical aspects in the design of socio-technical artifacts.

Paper 3. A view of the societal repercussions of the collaborative use of information technology and resulting ethical questions is developed by the paper "Analyse der ethischen Fragestellungen bei der Konstruktion von digitalen Plattformen" ("Analysis of Ethical Issues in the Construction of Digital Platforms") by Olga Levina. Considering the four dimensions Privacy, Access, Property and Accuracy, the paper reflects on ethical aspects of the governance structures of digital platforms. The examination demonstrates that over time an information asymmetry to the benefit of platform operators grows, which provides platform operators with instruments of power that potentially promote abuse. As a result, the paper argues for a socio-political debate about ethical questions around the construction of digital platforms.

Paper 4. Nudging has become a widespread mechanism in interactive and persuasive technologies, given its potential to influence the decision-making process of users and, eventually, modify their behavior. In the context of assistive technologies, nudging can be used to promote healthy behaviors and increase the independence of users (e. g., elders or people with an impairment). In their paper "Moral Challenges in Modeling and Simulation of Behavior Change in Care”, Stephanie C. Rodermund, Fabian Lorig, and Ingo J. Timm discuss the ethical implications of modeling and simulating nudging mechanisms and their corresponding user reactions. As they point out, such research and engineering practices entail ethical risks related to safety and privacy, among other concerns. Nonetheless, from a utilitarian perspective, once the risks have been analyzed and managed, the potential benefits in the well-being and independence of users makes nudging a convenient feature in assistive technologies.

Paper 5. The short paper "Das Wertequadrat als Werkzeug der Wirtschaftsinformatik" ("The Square of Values as a Tool in Business Informatics") by Alexander Rachmann addresses ethical questions on the methodical level of Business Informatics. It suggests to incorporate a conceptual tool called Square of Values into the methodical range of the discipline. The tool provides a systematic approach to find a balance between a pair of conflicting ethical values which both appear desirable. Together with 
an example of an ethical conflict in the domain of health-care oriented Smart Home applications, which targets the conflicting values of controlling a person's health status versus respecting a person's privacy, the paper suggests to connect the Square of Values with established modeling techniques for goals systems in Business Informatics.

As a whole, the contributions demonstrate that there is indeed much potential and need for research on ethical aspects in the objects and the methods of Business Informatics. Considering the range of topics discussed in the papers, it is clear that ethical questions are not placed at the margins of Business Informatics, but are instead entrenched in the very core subjects of the discipline.

\section{Conclusions}

The workshop Ethics and Morality in Business Informatics (EMoWI'19) was held in its first edition at the $14^{\text {th }}$ International Conference on Wirtschaftsinformatik (WI 2019) in Siegen. We hope to have reinforced that the study of ethics and morality has an important place in Business Informatics, and that many areas in the field are worthy, and actually in need, of a careful study as to their moral implications. If anything, it can be expected that the ongoing digital transformation will further advance the impact, and thus the ethical relevance, that information systems will have for all people's life.

Many colleagues have contributed to the success of this first edition of the Workshop on Ethics and Morality in Business Informatics, so we would like to express our appreciation. We are grateful to the international program committee members, who have carefully reviewed the submitted papers. We sincerely thank the authors who were inspired by the topic of the workshop and have submitted papers for consideration; also, we thank those authors whose paper was accepted, for presenting their work in the workshop and participating in the lively debates. Last but not least, we would like to thank the organizing committee members of the WI 2019 conference for their support.

The workshop proceedings have been published at http://ceur-ws.org/Vol-2297.

\section{References}

1. Kant, I.: Critique of Pure Reason. Translated by Norman Kemp Smith. Macmillan, London (1929)

2. Meijers, A. (ed.). Philosophy of Technology and Engineering Sciences. Elsevier, Amsterdam, London (2009)

3. Bendel, O.: 300 Keywords Informationsethik. Grundwissen aus Computer-, Netz- und Neue-Medien-Ethik sowie Maschinenethik. Springer Fachmedien, Wiesbaden (2016)

4. Schoemaker, P. J. H.: The Expected Utility Model: Its Variants, Purposes, Evidence and Limitations. Journal of Economic Literature 20(2), 529-563 (1982)

5. Bentham, J.: An Introduction to the Principles of Morals and Legislation. In Two Volumes. A New Edition, Corrected by the Author. Vol. I. Pickering, London (1823)

6. Kant, I.: Groundwork of the Metaphysics of Moral. In: Gregor, M. Timmermann, J. (eds.) Immanuel Kant: Groundwork of the Metaphysics of Morals. Cambridge University Press, Cambridge, 1-72 (2012) 
7. Friedman, B., Hendry, D. G., Borning, A.: A Survey of Value Sensitive Design Methods. Foundations and Trends in Human-Computer Interaction 11(2), 63-125 (2017)

8. Ferrario, M. A., Simm, W., Forshaw, S., Gradinar, A., Smith, M. T., Smith, I.: Values-first SE: research principles in practice. In: Companion Proceedings of the 38th International Conference on Software Engineering (ICSE 2016), pp. 553-562. ACM, New York (2016)

9. Aydemir F. B., Dalpiaz, F.: A Roadmap for Ethics-Aware Software Engineering. In: Proceedings of FairWare'18: IEEE/ACM International Workshop on Software Fairness, Gothenburg, Sweden, May 29, 2018 (FairWare '18). ACM, New York (2018)

10. Winter, E., Forshaw, S., Ferrario, M. A.: Measuring human values in software engineering. In: Proceedings of the 12th ACM/IEEE International Symposium on Empirical Software Engineering and Measurement (ESEM '18), Article 48. ACM, New York (2018)

11. España, S., Brinkkemper, S.: Responsible software: a research agenda to help enterprises become more sustainable. In: 4th International Conference on ICT for Sustainability (ICT4S 2016), Amsterdam, pp. 141-150. Atlantis Press, Paris (2016) 